\title{
Clinical Reasoning: A 40-Year-Old Woman With Scapular Winging and Dysphonia
}

Mohammad Aladawi, MD, Michael Punsoni, MD, and Ezequiel Piccione, MD

Neurology ${ }^{\circledR}$ 2021;97:503-507. doi:10.1212/WNL.0000000000012179
Correspondence

Dr. Aladawi

mohammad.aladawi@

unmc.edu

\section{Section 1}

A 40-year-old woman presented to the neuromuscular clinic for evaluation of chronic right shoulder weakness of 1-year duration. During that time, she noticed progressive difficulties lifting her right arm overhead and reaching for objects on the back seat of her car. Around 3 months after the onset of shoulder weakness, she started to develop an intermittent achy sensation behind the right ear and hoarseness of her voice. She noted difficulty talking over loud noises and in phone conversations. She denied vision, taste, or hearing changes, dysphagia, dyspnea, numbness, or weakness in other limbs.

The patient did not have any prior shoulder trauma or past surgical history involving her neck. She denied severe pain in the shoulder region prior to the onset of symptoms. There was no family history of shoulder muscle weakness or gait impairment.

Neurologic examination demonstrated normal mental status examination; the patient's speech was fluent, and she was able to name, repeat, and comprehend. Her voice was hoarse with a reduced pitch but all words were intelligible, and no nasal or strained quality was present. Cranial nerve examination showed reduced soft palate elevation on the right side. Gag reflex was present. Motor examination demonstrated right shoulder drop, atrophy of right trapezius muscle, and lateral displacement of the right scapula at rest that worsened with shoulder abduction. Full active forward flexion of the right shoulder was limited to $120^{\circ}$ but improved to $180^{\circ}$ when lying supine. Examination of individual muscle groups demonstrated $4 / 5$ weakness in left lateral neck rotation, 5-/5 neck flexion, and 4/5 weakness in right shoulder shrug. Sensory and deep tendon reflexes examination disclosed no deficits.

\section{Question for Consideration:}

1. Where would you localize this neurologic process?

\section{GO TO SECTION 2}




\section{Section 2}

Neurogenic scapular winging can be due to long thoracic neuropathy, spinal accessory neuropathy, or less commonly dorsal scapular nerve involvement. Neurologic examination can point to the nerve involved. Serratus anterior muscle weakness (long thoracic nerve) causes medial winging of the scapula, which is more prominent with forward shoulder flexion. Scapular winging is lateral and worsens with shoulder abduction in lesions of spinal accessory nerve. ${ }^{1}$ Winging from rhomboid weakness (dorsal scapular nerve) presents with pain at the medial border of the scapula and becomes more prominent by having the patient push the elbow backward against resistance with the hand on the waist. ${ }^{2}$

The combination of shoulder drop, trapezius atrophy, lateral scapular winging that worsens with abduction, and weakness of ipsilateral sternocleidomastoid (neck flexion and contralateral neck rotation) suggested a spinal accessory neuropathy in our patient. Neurologic examination also demonstrated voice changes consistent with dysphonia, which together with the finding of reduced palatal elevation could point to vagus nerve dysfunction. Retroauricular pain could be suggestive of glossopharyngeal nerve dysfunction (innervates retroauricular skin) or nonspecific referred pain.

To evaluate further the right scapular winging, the patient was referred for EMG testing. In this study, standard motor and sensory nerve conduction studies of the upper limb were normal. Needle examination showed fibrillation potentials and reinnervation (large, long motor units with reduced recruitment) in the right trapezius muscle. Serratus anterior, rhomboids, infraspinatus, cervical paraspinal, and limb muscles were normal. The patient was also referred to ENT service for further evaluation of her dysphonia. Laryngoscopy revealed right true vocal fold paralysis.

\section{Questions for Consideration:}

1. What etiologies are you considering?

2. What ancillary testing is indicated next? 


\section{Section 3}

The EMG results pointed to a right spinal accessory neuropathy or C3-C4 radiculopathy. Preserved sensory nerve action potentials, as in this case, normally suggest an abnormality proximal to the dorsal root ganglion. However, the spinal accessory nerve lacks a sensory branch to evaluate in nerve conduction studies so in the absence of cervical paraspinal muscle involvement the distinction between preganglionic and postganglionic pathology cannot be made. MRI C-spine was obtained, which did not reveal significant neuroforaminal stenosis in the upper cervical segments. At this point, the clinical picture was consistent with multiple cranial neuropathies. We suspected the cause of the scapular winging was a spinal accessory neuropathy but the etiology remained unclear.

Lesions of the spinal accessory nerve are most commonly iatrogenic (i.e., posterior cervical lymph node biopsy) and affect the distal portion of the nerve innervating trapezius but sparing sternocleidomastoid muscle. Proximal and intracranial lesions of the accessory nerve affect the sternocleidomastoid and trapezius muscles, as was seen in this case.

MRI brain and neck soft tissue was then obtained, which revealed an enhancing mass on the right jugular foramen suspicious for meningioma or schwannoma (figure 1). Atrophy of the right trapezius and sternocleidomastoid muscles was also noted on imaging.

The patient underwent craniotomy and a tumor originating in the right glossopharyngeal nerve was resected. This tumor was compressing but not infiltrating the vagal and the spinal accessory nerves. Pathology revealed a benign nerve sheath tumor with mixed features of schwannoma and neurofibroma (figure 2).

The patient had rapid improvement of her voice in the next 3 months and slower but steady improvement of her scapular winging over the next year. Dynamic muscle transfer, which is typically performed in cases resistant to conservative treatment, was not required. For trapezius muscle palsy, this surgery involves the lateral transfer of the rhomboid major, rhomboid minor, and levator scapulae tendons to replace lower, middle, and upper trapezius muscle fibers, respectively. ${ }^{3}$ This improves the function of the trapezius muscle and stabilizes the scapula.

\section{Discussion}

The case presented was due to a neoplastic spinal accessory neuropathy in the context of multiple cranial nerve deficits including dysphonia (vagus nerve) and retroauricular pain (glossopharyngeal nerve). This constellation is called jugular foramen syndrome (Vernet syndrome). ${ }^{4}$ Our case emphasizes the fact that proximal spinal accessory neuropathy is typically not iatrogenic and compressive or tumoral lesions should be sought. . $^{5}$

The jugular foramen is split by a fibrous septum into 2 parts: a smaller anteromedial portion (pars nervosa) and a larger posterolateral portion (pars vascularis). The pars nervosa carries the inferior petrosal sinus and the glossopharyngeal, vagus, and accessory nerves, while the pars vascularis contains the sigmoid-jugular complex. The hypoglossal canal lies posteromedially and in close proximity. Both anatomical structures lie within the intercondylar space. ${ }^{4}$ Lesion confined to the jugular foramen can result in glossopharyngeal, vagus, and accessory nerve palsies. The diagnosis of neoplastic jugular foramen syndrome can be difficult because cranial nerve involvement develops gradually, in both a variable chronological fashion and variable impairment of each cranial nerve, as was the case in the patient presented.

Lesions affecting the jugular foramen can also extend beyond this structure to involve the hypoglossal canal. Collet-Sicard syndrome is a neurologic disorder that manifests with glossopharyngeal, vagus, accessory, and hypoglossal nerve palsies due to lesions affecting the jugular foramen and intercondylar

Figure $1 \mathrm{MRI}$ Examination of the Brain
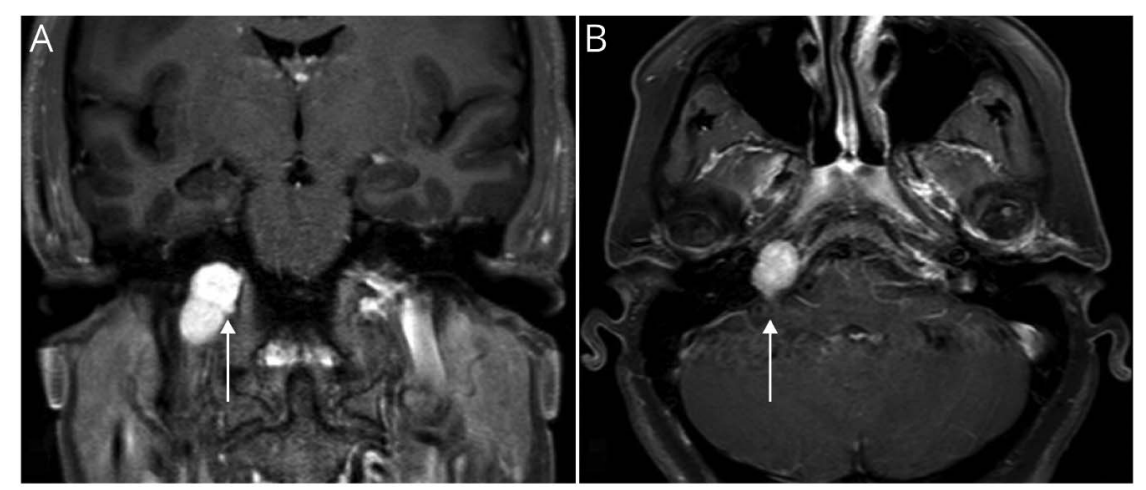

Coronal (A) and axial (B) T1-weighted postcontrast sequences with fat saturation. Right jugular foramen mass $(1.7 \times 1.6 \times 2.3 \mathrm{~cm})$ demonstrates typical dumbbell shape and prominent homogenous contrast enhancement (arrows). 


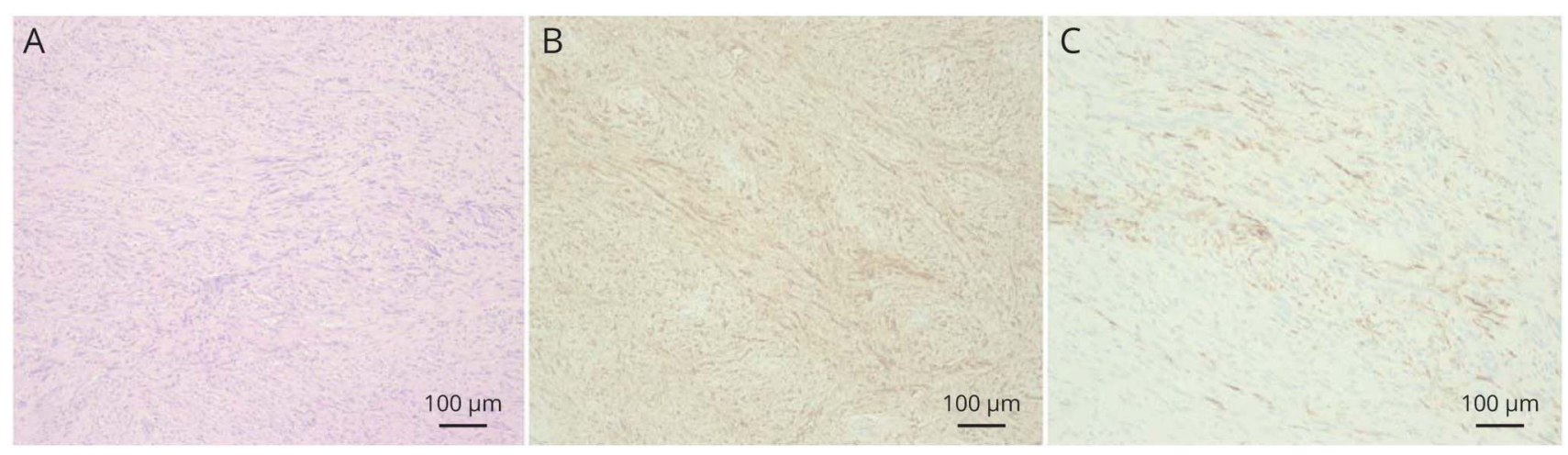

Hematoxylin \& eosin at $100 \times($ A) shows a neoplasm with characteristic spindle cells and a collagenous stroma. Immunostaining at $100 \times$ demonstrates diffuse positivity for S100 (B) while CD34 (C) shows limited reactivity in tumor cells.

space. Villaret syndrome is when a patient presents with Horner syndrome in addition to glossopharyngeal, vagus, accessory, and hypoglossal nerve palsies, which signifies carotid sheath involvement. ${ }^{6}$ Etiologies of jugular foramen syndrome include primary tumors (meningioma, schwannoma, cholesteatoma), inflammation (meningitis, malignant otitis media), bone metastasis, carcinomatous meningitis, and internal jugular vein thrombosis. ${ }^{7,8}$

The pathology in our case revealed findings consistent with a "hybrid" benign nerve sheath tumor. The presence of capsule, axons situated peripherally within the lesion, and diffuse S100 immunopositivity all support schwannoma, while the prominent collagen within the tumor and lack of prominent Verocay bodies suggested possible neurofibroma histology. 9

Neurofibromas typically develop in skin as nodular or polypoid lesions.' Schwannomas most commonly affect the vestibulocochlear nerve followed by the trigeminal nerve. ${ }^{10}$ Schwannomas can be distinguished from other primary intracranial tumors by certain radiologic features. In this case, the jugular foramen mass demonstrated a dumbbell shape and prominent diffuse contrast enhancement, which are typical nerve sheath tumor radiologic features. ${ }^{11}$ Meningioma, on the other hand, typically presents a dural-tail sign on imaging. ${ }^{12}$ The benign nature of the encountered mixed nerve sheath tumor, which seemed to cause deficits by compression rather than invasion or infiltration, explains the good recovery our patient had postresection.

Parsonage-Turner syndrome (or neuralgic amyotrophy) is a common noniatrogenic cause of scapular winging. In this syndrome, trapezius muscle is involved in $20 \%$ of the cases and can sometimes present with associated dysphonia mimicking a partial Vernet syndrome. ${ }^{13,14}$ The muscle weakness in this inflammatory monophasic condition is typically preceded by severe shoulder pain and most commonly causes a more diffuse and patchy motor involvement of the long thoracic, suprascapular, axillary, and anterior interosseous nerves. ${ }^{15}$

Scapular winging is a frequent referral to neuromuscular clinics and has a broad differential diagnosis. Detailed clinical examination and EMG can be informative. A neoplastic cause, although rare, has to be considered in unilateral progressive scapular winging and especially if no history of trauma or prior medical procedures is present.

\section{Study Funding}

The authors report no targeted funding.

\section{Disclosure}

The authors report no disclosures relevant to the manuscript. Go to Neurology.org/N for full disclosures.

\section{Appendix Authors}

\begin{tabular}{|c|c|c|}
\hline Name & Location & Contribution \\
\hline $\begin{array}{l}\text { Mohammad } \\
\text { Aladawi, MD }\end{array}$ & $\begin{array}{l}\text { Department of Neurologic } \\
\text { Sciences, University of } \\
\text { Nebraska Medical Center }\end{array}$ & $\begin{array}{l}\text { Drafting/revision of the } \\
\text { manuscript for content, } \\
\text { including medical writing for } \\
\text { content; major role in the } \\
\text { acquisition of data; study } \\
\text { concept or design; analysis } \\
\text { or interpretation of data }\end{array}$ \\
\hline $\begin{array}{l}\text { Michael } \\
\text { Punsoni, MD }\end{array}$ & $\begin{array}{l}\text { Department of Pathology } \\
\text { and Microbiology, University } \\
\text { of Nebraska Medical Center }\end{array}$ & $\begin{array}{l}\text { Major role in the acquisition } \\
\text { of data, analysis or } \\
\text { interpretation of data, had a } \\
\text { major role in acquiring and } \\
\text { preparing the pathology } \\
\text { images for revised } \\
\text { manuscript, helped in } \\
\text { writing sections in the } \\
\text { discussion }\end{array}$ \\
\hline $\begin{array}{l}\text { Ezequiel } \\
\text { Piccione, MD }\end{array}$ & $\begin{array}{l}\text { Department of Neurologic } \\
\text { Sciences, University of } \\
\text { Nebraska Medical Center }\end{array}$ & $\begin{array}{l}\text { Drafting/revision of the } \\
\text { manuscript for content, } \\
\text { including medical writing for } \\
\text { content; major role in the } \\
\text { acquisition of data; study } \\
\text { concept or design; analysis } \\
\text { or interpretation of data }\end{array}$ \\
\hline
\end{tabular}




\section{References}

1. Seror P, Lenglet T, Nguyen C, Ouaknine M, Lefevre-Colau MM. Unilateral winged scapula: clinical and electrodiagnostic experience with 128 cases, with special attention to long thoracic nerve palsy. Muscle Nerve. 2018;57(6): 913-920.

2. Tsivgoulis G, Vadikolias K, Courcoutsakis N, Heliopoulos I, Stamboulis E, Piperidou C. Teaching Neuroimages: Differential diagnosis of scapular winging. Neurology. 2012;78(17):e109.

3. Bigliani LU, Compito CA, Duralde XA, Wolfe IN. Transfer of the levator scapulae, rhomboid major, and rhomboid minor for paralysis of the trapezius. J Bone Joint Surg Am. 1996;78(10):1534-1540.

4. Iwasaki K, Kondo A. Accessory nerve neurinoma manifesting with typical jugular foramen syndrome. Neurosurgery. 1991;29(3):455-459.

5. Lee S, Yang S, Lee J, Kim I. Spinal accessory neuropathy associated with the tumor located on the jugular foramen. Ann Rehabil Med. 2013;37(1):133-137.

6. Petrović S, Grozdanović D, Kovačević P, Višnjić M, Petrović D. Collet Sicard syndrome as atypical presentation of neck fibrosarcoma: a case report. Bosn J Basic Med Sci. 2011;11(2):137-140.
7. Neo S, Lee KE. Collet-Sicard syndrome: a rare but important presentation of internal jugular vein thrombosis. Pract Neurol. 2017;17(1):63-65.

8. Vogl TJ, Bisdas S. Differential diagnosis of jugular foramen lesions. Skull Base. 2009;19(1):3-16.

9. Feany MB, Anthony DC, Fletcher CD. Nerve sheath tumours with hybrid features of neurofibroma and schwannoma: a conceptual challenge. Histopathology. 1998;32(5): 405-410.

10. Hsu L. Intracranial schwannomas. In: Newton HB, Jolesz FABT, eds. Handbook of Neuro-Oncology Neuroimaging (2nd edition). Academic Press; 2008:408-418.

11. Crist J, Hodge JR, Frick M, et al. Magnetic resonance imaging appearance of schwannomas from head to toe: a pictorial review. J Clin Imaging Sci. 2017;7:38.

12. Lyndon D, Lansley JA, Evanson J, Krishnan AS. Dural masses: meningiomas and their mimics. Insights Imaging. 2019;10(1):11.

13. Van Alfen N, Van Engelen BGM. The clinical spectrum of neuralgic amyotrophy in 246 cases. Brain. 2006;129(2):438-450.

14. Samarà L, Valls-Sole J, Caballero M. Dysphonia as an unusual debut of ParsonageTurner syndrome. Head Neck. 2013;35(7):E229-E230.

15. Ferrante MA, Wilbourn AJ. Lesion distribution among 281 patients with sporadic neuralgic amyotrophy. Muscle Nerve. 2017;55(6):858-861.

\section{COVID-19 and Neurologic Disease: Call for Papers!}

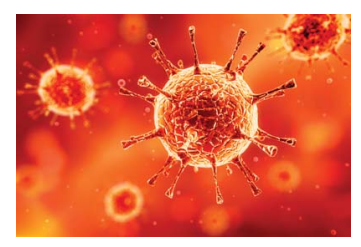

The editors of Neurology are interested in papers that address the neurological aspects of COVID-19 infection and challenges to the management of patients with chronic neurological conditions who have, or are at risk for, the infection. Relevant papers that pass initial internal review will undergo expedited peer review and online publication. We will consider papers posted in preprint servers.

Submit observational studies and clinical trials as Articles and case series and case reports under the Clinical/Scientific Notes category to https://submit.neurology.org/ today!

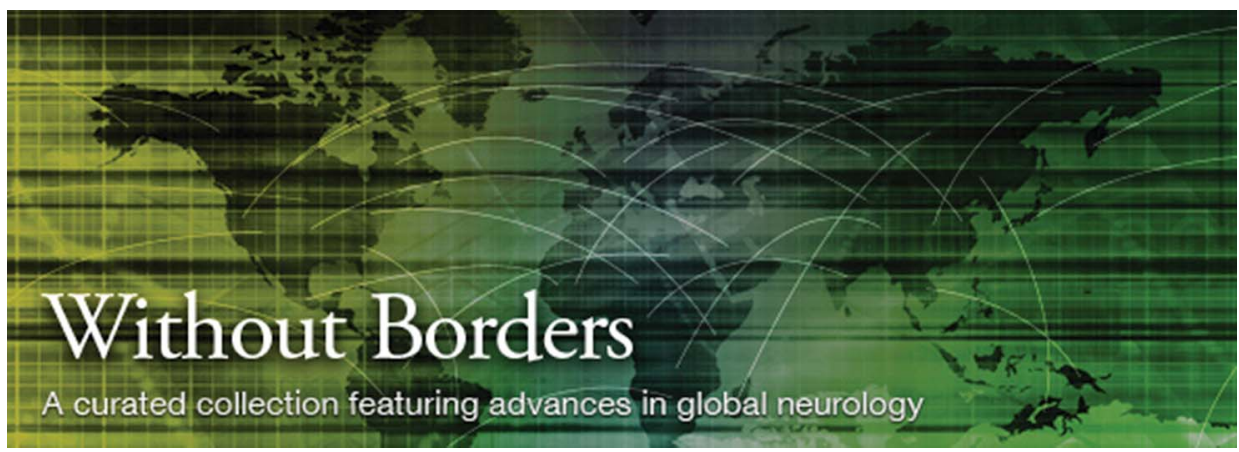

\section{Without Borders - A curated collection featuring advances in global neurology}

This Neurology ${ }^{\circledR}$ special interest website is the go-to source for tracking science and politics of neurology beyond the United States, featuring up-to-the-minute blogs, scholarly perspectives, and academic review of developments and research from Neurology journals and other sources. Curated by Gretchen L. Birbeck, MD, MPH.

\section{Expand your world view at Neurology.org/woborders.}




\section{Neurology}

Clinical Reasoning: A 40-Year-Old Woman With Scapular Winging and Dysphonia

Mohammad Aladawi, Michael Punsoni and Ezequiel Piccione

Neurology 2021;97;503-507 Published Online before print May 12, 2021

DOI 10.1212/WNL.0000000000012179

This information is current as of May 12, 2021

\section{Updated Information \&} Services

References

Subspecialty Collections

Permissions \& Licensing

Reprints including high resolution figures, can be found at: http://n.neurology.org/content/97/10/503.full

This article cites 14 articles, 3 of which you can access for free at: http://n.neurology.org/content/97/10/503.full\#ref-list-1

This article, along with others on similar topics, appears in the following collection(s):

Cranial neuropathy

http://n.neurology.org/cgi/collection/cranial_neuropathy

Nerve tumor

http://n.neurology.org/cgi/collection/nerve_tumor

Neuropathic pain

http://n.neurology.org/cgi/collection/neuropathic_pain

Peripheral neuropathy

http://n.neurology.org/cgi/collection/peripheral_neuropathy

Surgical therapy-tumor

http://n.neurology.org/cgi/collection/surgical_therapytumor

Information about reproducing this article in parts (figures,tables) or in its entirety can be found online at:

http://www.neurology.org/about/about_the_journal\#permissions

Information about ordering reprints can be found online:

http://n.neurology.org/subscribers/advertise

Neurology ${ }^{\circledR}$ is the official journal of the American Academy of Neurology. Published continuously since 1951, it is now a weekly with 48 issues per year. Copyright () 2021 American Academy of Neurology. All rights reserved. Print ISSN: 0028-3878. Online ISSN: 1526-632X.

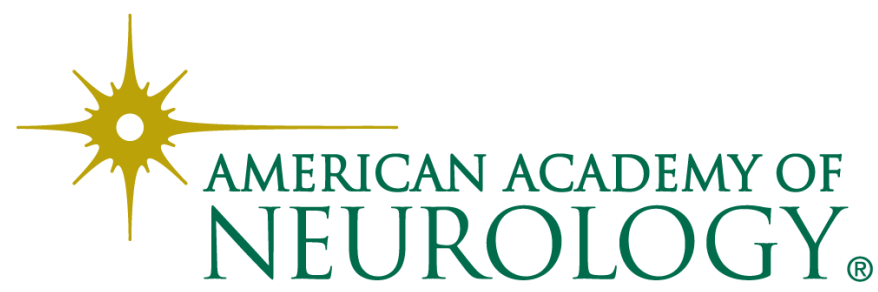

